\title{
PRESENTACIÓN: EDICIÓN DIGITAL Y EDICIÓN CRÍTICA
}

\author{
RAMÓN VALDÉS (Prolope)
}

$\mathrm{D}$

esde hace un tiempo, en nuestro grupo de investigación, PROLOPE, nos venimos planteando la necesidad de adentrarnos, de una u otra manera, por el camino de la filología digital. En los distintos artículos que se presentan en este número del Anuario Lope de Vega se reflexiona sobre el abanico de posibilidades editoriales que el cauce electrónico nos abre, se ofrece información sobre programas y herramientas que ya están al alcance del filólogo y se aportan ejemplos concretos de ediciones digitales en curso así como de casos textuales para los que tal vez la solución informática sea la mejor de las posibles.

Estas que, hasta ahora, llamábamos «nuevas tecnologías» (marbete ante el que desde hace un tiempo no puede dejar de apostillarse «bueno, ya no tan nuevas») están pasando de largo por la Filología Española sin que la vieja dama, en lo que a la edición crítica se refiere, se inmute. Empezábamos a enorgullecernos de estar dando un paso enorme y decidido, como efectivamente está siendo, en el terreno de la edición rigurosa de nuestros clásicos, y aquí llega la Filología Digital, cuando todavía no habíamos alcanzado la meta, para dejarnos de nuevo atrás. Hará ya una década los especialistas comentaban la riqueza de herramientas al alcance del filólogo y de propuestas de ediciones críticas electrónicas en diferentes tradiciones literarias. Sin embargo, en la Filología Española, y todavía más concretamente en España, todavía en 2014, seguimos aferrados a métodos tradicionales, diría artesanales, en la elaboración de nuestras ediciones críticas salvo contadísimas excepciones. Cabe contar entre las excepciones, por ejemplo, los loables proyectos de Eduardo Urbina (The Cervantes Project), Dorothy S. Severin (Cancioneros. An Electronic Corpus of 15th Century Castillian Cancionero Manuscript) o Carmen Isasi (Proyecto Andrés Poza).

En cuanto a la presencia de textos teatrales del Siglo de Oro en la red, seguimos en esa fase que J. M. Lucía Megías bautizó como «incunable del hipertexto». Aunque no ediciones críticas, pasos en el buen camino: ya de hace unos años la edición de Rosa Navarro de El perro del hortelano; El divino cazador de 
Calderón editada por E. Pellús y Manuel Sánchez en la Biblioteca Virtual Miguel de Cervantes; y la muy reciente de La entretenida cervantina de John O'Neill, en el ámbito del proyecto Out of the Wings dirigido por Catherine Boyle. Por desgracia, paralelamente, aún siguen surgiendo proyectos en los que se privilegia la cantidad de los textos sobre la calidad, algo sobre lo que Lucía Megías ya dio la voz de alarma. Hoy vemos cómo las ediciones electrónicas de textos poco cuidados se replican y propagan por la red con su efecto multiplicador e incluso pasan al mundo del libro impreso con los errores que introdujeran.

Es lo cierto que frente a estas carencias o este desinterés en el ámbito de la edición crítica digital, se están dando pasos muy importantes en muchos otros campos dentro de la investigación del Teatro del Siglo de Oro. Desde las bases de datos de texto completo que permiten generación automática de concordancias, hasta bases de datos como las propuestas en ArTELOPE, DICAT, CATCOM, etc.

Sin embargo, si hablamos de ediciones críticas electrónicas, todavía se observa en algunos filólogos una actitud reacia. Unos por escepticismo y desesperanza al ver la eterna promesa de la maravillosa edición crítica electrónica nunca realizada, otros por desconocimiento, otros por una posición fetichista de apego al objeto «libro» y a métodos tradicionales que piensan que van a ser trastocados (y tal vez no les falte razón; tal vez sean necesarios algunos replanteamientos), al final parecen ser más los renuentes, y sin duda la situación es de práctico estancamiento.

Nos encontramos en un momento cultural y científico revolucionario y apasionante. Y todos, más tarde o más temprano, habremos de entrar por ese camino en el terreno social, político, cultural, artístico, científico. De una manera muy clara, está concernida la ciencia en sus más diversos ámbitos, entre otros, por supuesto, los humanísticos y los filológicos.

Prolope asume el reto. Percibe como una obligación para un grupo de investigación que se ocupa de la edición crítica del teatro de Lope de Vega abordar y compartir una reflexión a propósito de la edición crítica digital.

El punto de partida de este volumen (Valdés) es eminentemente pragmático: ¿por qué nos puede interesar la opción digital para la elaboración de ediciones críticas?, ¿la edición digital resuelve problemas que parecían insalvables en ediciones en papel?, ¿comporta, por el contrario, también otros problemas de carácter práctico al investigador?, ¿ofrece ventajas en la difusión y divulgación del saber y de los resultados de investigación? La verdad es que ha sido difícil decidir el orden de publicación de los artículos. Porque frente a ese punto de partida eminentemente 
pragmático, cabía también empezar desde las perspectivas más abstractas y teóricas que ofrece Paul Spence. Sin embargo, podríamos decir que a la vez, desde esos puntos de partida teóricos, el artículo de Spence ofrece magistralmente respuestas y soluciones prácticas a las cuestiones abiertas por Valdés. Por otro lado, el orden finalmente decidido facilita la entrada en el tema a los más legos. No estaría mal si alguno de esos que se declaran reacios acabaran planteándose la necesidad de asumir lo que ya es una nueva realidad. A continuación, y frente a la desorientación que muchos filólogos de a pie podemos sentir frente a este mundo que desconocemos, en el artículo de Francesca Tomasi se nos brinda un panorama de herramientas ya fácilmente disponibles para la elaboración de ediciones críticas y el análisis textual, para acabar ofreciendo una propuesta de un entorno web desarrollado al servicio del editor. Y para terminar, el artículo de Nàdia Revenga presenta eso tan perseguido y ansiado: por fin una edición crítica electrónica que está en curso, pero ya próxima a finalizar, de una obra de teatro del Siglo de Oro. En el apartado de reseñas, Eugenio Maggi analiza la edición de John O’Neill de La entretenida de Cervantes.

Aquí acabaría la presentación de todos los contenidos sobre edición digital y edición crítica de este número del Anuario Lope de Vega. Sin embargo se debe aludir todavía a otro par de artículos: uno presente en este mismo número, aunque ahora desde un punto de vista estrictamente filológico. El artículo de Stefania Capoia funciona como la perfecta ilustración de un problema filológico y editorial cuya mejor solución, a nuestro modo de ver, es la digital. El entramado de variantes, manos, estratos de intervención y textos presentes en el manuscrito autógrafo de La buena guarda y La encomienda bien guardada pide una solución editorial digital. Aunque, como decíamos, la autora se detiene en las cuestiones puramente filológicas y propuso en su edición una solución en papel (de la que, de hecho, se ofrecen varias páginas de ejemplo). Para el próximo número de nuestra revista queda prometida una presentación de un proyecto de edición digital de La dama boba en el que viene trabajando ya hace un tiempo Marco Presotto. Considérese, en cierto modo, extensión o segunda entrega de este número sobre edición crítica y edición digital.

Para acabar, la sección de artículos se cierra con el de Antonio Sánchez Jiménez en torno a las posibles implicaciones y lecturas políticas del romancero morisco de Lope defendidas por algunos críticos y aquí cuestionadas. Es colofón oportuno para subrayar que, aunque se planteen temas monográficos en nuestro Anuario Lope de Vega. Texto, literatura, cultura, habrá cabida para artículos apropiados para el tema de interés más general de la revista y de sus lectores. 